\title{
Analysis of the Influence of E-commerce on the Innovative Development of Marketing
}

\author{
Qiulian Sun \\ Jiangxi Vocational Techical College Of Industry \& Trade, Jiangxi, Nanchang, 330038
}

key words E-commerce; Innovation and Development; Marketing; Influence

\begin{abstract}
In the continuous development of society and the continuous innovation of science and technology, it is obvious that the development of e-commerce is really rapid, but its development, at the same time, has led to the development of many industries, but also brought a lot of challenges. Under its leadership, the economic changes in the market more diverse, for the economic development of innovation to provide a source of power, greatly accelerated the economic renewal. Therefore, this article makes the corresponding analysis and view on the marketing of e-commerce, and tries to show and display its great potential.
\end{abstract}

\section{Introduction}

The development of society brings many new industries, among which e-commerce is a new product of the new era, which deeply affects the economic and social development of our country. Especially at the present level of market economy, more and more economic theories and economic means can not be separated from the participation of electronic commerce.

\section{The influence of Electronic Commerce on the Development of Marketing Innovation}

\subsection{Make a huge change to the traditional marketing mode}

As we all know, in the past, we used to advertise the products through advertising, but as consumers, we can not really experience the convenience and rapidity brought by it, so, how to make consumers experience the value of it, this is really worth thinking about, consumers guide according to the current actual situation, rational consumption. In the case of such rapid economic development, the traditional marketing model seems to be very difficult, many drawbacks gradually emerged, for example, in marketing, as marketers can not better communicate with customers, can not provide a more powerful guarantee, at the same time, people's living standards Seek in the continuous increase, therefore, the traditional marketing means through advertising, first has to be very weak. E-commerce is a revolutionary change to ordinary marketing, so that their communication is gradually reduced, the company can directly sell products, customers can directly understand through the platform, whether in terms of human and material resources, or in the effect, there are obvious improvements.

\subsection{Change the way consumers spend}

In today's society, it is the age of the network, and the advantage of e-commerce is better displayed. As if it is a necessity in the daily life of people, it is a part of life, and now, we can receive our favorite articles at home, and can also choose, and then buy the products we need with a low price after many comparison. The emergence of such a pattern has also led to the disappearance of such a bargain, so that the act of being spoofed is also greatly reduced. Without being limited to this, the consumer may have more specific preferences, so the customized product can be more in line with the consumer's needs, and the consumer can obtain more High-quality new products, and merchants, or manufacturers, can constantly reform and provide more services for people. Therefore, in this kind of environment, the contact between the consumer and the enterprise can be brought closer, and the higher quality product can be provided for the consumer, and the better profit and the demand can be brought for the merchant. 


\subsection{Reform the way things are}

The rapid development of science and technology, the power of social progress, the use of ecommerce become very broad, and more people are receiving, the user quantity is increasing constantly, and the related aspects are also various. if that enterprise want to advance, e-commerce must provide a strong guarantee for it, but in the present case, there are many difficulties and shortcomings in this aspect of our country, such as the insufficient service level of the sales staff, the problem of service attitude, the problem of the means and the target, etc., These are very deadly weaknesses. Therefore, it is necessary to change the quality of the marketing, the traditional mode must be changed, and the combination of the actual situation Reform was carried out in 2005. Ecommerce can improve the development and production of an enterprise to a greater extent, not only in the cost, but also greatly saves powerlessness, which is a very effective way. It can greatly improve the status of enterprises and achieve more powerful development of enterprises. For users with desire to shop, big data's application is undoubtedly very helpful, but for users who do not want to shop, pushing ads is like harassing information, which makes people feel uncomfortable. However, for ecommerce, it is very important to understand the needs and consumption habits of customers. Big data's application will undoubtedly bring great benefits to businesses. General In the case of a customer looking for a commodity or service, the traditional search results can have a large amount of value-free information, and the time required is long, but if a personalized presentation search result is carried out for the user, the time for the user to find the heart instrument product will be greatly shortened. For a merchant, it is necessary to sell more goods, and it is necessary for the consumer to save more time to find the goods, and the application of the large data brings a win-win result to both. The personalized search results displayed by e-commerce will not be $100 \%$ clicked by the user, and the lack of sufficient and effective information data is difficult to deduce the real result. this needs to be The algorithm is optimized to complete the analysis of large-scale data to improve the accuracy of the search results. It's always an annoying thing to waste time on a web site. After using big data, it can be reduced from one hour to a few minutes, and it's not. Amazon's shopping site is one of the most successful e-commerce sites today. Its technology is leading, and its product recommendations are particularly laudable, and a good user evaluation has been accumulated over the years. In a nutshell, that big data provide a potential for customization of the user experience, which brings great convenience to shopping.

Through the 18-year-old meeting, the internet + has a qualitative leap in the status of people, and the development of e-commerce has been gradually improved under the leadership of science and technology level. Now, it's everywhere, it's the necessity of life. Compared with the traditional ecommerce, there are more differences in e-commerce under the Internet, which requires us to have a better ability of thinking and innovation. E-commerce can be divided into the broad sense, the narrow sense, the general is the mobile phone computer and other electronic devices, the narrow sense is a series of activities and ways through the Internet.

\section{The way to give marketing to e-commerce}

\subsection{Innovative manner}

E-commerce has carried on the thorough research to the consumer consumption idea, the goal is to attract more customers, causes the product to obtain the bigger marketing. Therefore, the first thing to ensure is to have more innovative thinking and ways, so that the marketing system can be more fully developed, so that consumers can get a better satisfactory consumption experience, but also have more choices and requirements. Taobao was founded to improve people's living standards to meet people's needs and development potential. A wide range of products is its great advantage, whether you need high-end products, or affordable products, you can gain, the same As a result, many virtual transactions can also give you a rich experience, such as charging and vip, and so on. Whether you are a line or an offline person, you can experience the great advantage brought by it, and it is not to be ignored that after-sales problems do need to be guaranteed, only so that more security can be brought to the consumer, and the consumer can negotiate with the business, and if there is a problem 
in the aspect of quality, The merchant may provide a return or a replacement to better serve the consumer.

\subsection{Understand the requirements of consumers}

Even if the necessary prerequisite for the existence of e-commerce, that is, customers are God, need to put a long-term perspective on consumers. E-commerce, in production and consumption, has a hub function. Therefore, the production process is also an inseparable part. Manufacturers are responsible for the production of products, through marketing personnel to sell, so there is a close relationship with consumption. Consumers are the significance of the existence of enterprises, but also have a great contribution to the market, so a full understanding of consumers, can be conducive to the survival of enterprises in the development. At present, the service level of enterprises is not optimistic and is in a low level of water. Ping, the service side also seems a little rigid, the most important way is to sell products to consumers. E-commerce, in these years, has also been the corresponding development, the model is also gradually improved, so the current task of e-commerce is to connect all aspects, improve the level of sales, and finance all aspects of funds.

\section{Conclusion}

Although at present, China's e-commerce level still has a lot of development potential, but in the face of rising consumer demand now, has been unable to meet. Enterprises need to continuously improve the demand of consumers, timely make corresponding adjustments, through this way of continuous innovation and improvement, to provide consumers with more high-quality products, enterprises can also obtain more income, improve their status. In today's social background, e-commerce has a very important existence significance, through continuous innovation and innovation, let it have a stable position in the complex society today.

\section{References}

[1] The Analysis of the Influence of E-commerce on the Development of Marketing Innovation[J]. Cai Xiaofeng . Chinese Business Theory. 2019(10)

[2] On the influence of Electronic Commerce on the innovative Development of Marketing[J]. Rao Yuanli . Old brand marketing. 2019(02)

[3] The Influence of E-commerce on the Innovative Development of Marketing[J].Sule. Pay taxes. 2018(03)

[4] Research on the influence of Electronic Commerce on Marketing Innovation and its Countermeasures[J]. Yuxiang . Science and technology economic market. 2017(06)

[5] Research on the Marketing Model of the Enterprise in the E-commerce Environment of the New Period[J]. Limeng Financial community. 2019(09)

[6] Discussion on the Strategy of E-commerce to Promote the International Trade and Economic Development[J]. Jiaochen . Modern marketing. 2019(08)

[7] Research on Marketing Strategy Based on the Background of Electronic Commerce[J]. Zhangying. Modern commerce. 2019(08) 